Research Article

Francesco Aletta, Stefano Brinchi, Stefano Carrese, Andrea Gemma, Claudia Guattari, Livia Mannini, and Sergio Maria Patella*

\title{
Analysing urban traffic volumes and mapping noise emissions in Rome (Italy) in the context of containment measures for the COVID-19 disease
}

https://doi.org/10.1515/noise-2020-0010

Received Jun 29, 2020; accepted Jun 29, 2020

\begin{abstract}
This study presents the result of a traffic simulation analysis based on Floating Car Data and a noise emission assessment to show the impact of mobility restriction for COVID-19 containment on urban vehicular traffic and road noise pollution on the road network of Rome, Italy. The adoption of strong and severe measures to contain the spreading of Coronavirus during March-April 2020 generated a significant reduction in private vehicle trips in the city of Rome (-64.6\% during the lockdown). Traffic volumes, obtained through a simulation approach, were used as input parameters for a noise emission assessment conducted using the CNOSSOS-EU method, and an overall noise emissions reduction on the entire road network was found, even if its extent varied between road types.
\end{abstract}

Keywords: COVID-19; Italy's coronavirus epidemic; Containment Strategies; Transport Restriction; Traffic Simulation; Floating Car Data; Noise mapping; Urban Noise Pollution

\section{Introduction}

On February 20/2020, a young man in the Lombardy region of Italy was admitted with an atypical pneumonia that later proved to be COVID-19. In the next 24 hours there were

\footnotetext{
*Corresponding Author: Sergio Maria Patella: Faculty of Economics, Universitas Mercatorum, Piazza Mattei, 10, 00186 Rome, Italy; Email: sergiomaria.patella@unimercatorum.it

Francesco Aletta: Institute for Environmental Design and Engineering, The Bartlett, University College London - 14 Upper Woburn Place,WC1H 0NN London, United Kingdom

Stefano Brinchi: Rome Mobility Agency (Roma Servizi per la Mobilità), Via L. Gaurico 9, 00143 Rome, Italy

Stefano Carrese, Andrea Gemma, Claudia Guattari, Livia Mannini: Department of Engineering, Roma Tre University, Via Vito Volterra 62, 00146 Rome, Italy
}

๖ Open Access. @ 2020 F. Aletta et al., published by De Gruyter. (cc) BY License
36 more cases, none of whom had contact with the first patient or with anyone known to have COVID-19. This was the beginning of one of the largest and most serious clusters of COVID-19 in the world [1]. Italy has had 221,216 confirmed cases according to the Italian Ministry of Health [2], as of May 12, 2020, 17:00 h, and 30,911 deaths.

As reported by [3], the Decree issued on 8 March 2020 [4] provides urgent measures to combat and contain the spread of the COVID-19 virus in Lombardy and in the cities of: Modena, Parma, Piacenza, Reggio Emilia, Rimini, Pesaro-Urbino, Alessandria, Asti, Novara, VerbanoCusio-Ossola, Vercelli, Padova, Treviso, Venezia. The Decree issued on 9 March 2020 [5] extended to the whole national territory the restrictive measures envisaged by the previous Decree. The Decree provides that any movement of physical persons (both within the national territory and entering/exiting the country) must be avoided, except for proven work-related needs, situations of necessity or health reasons.

As part of these social distancing policies, the Italian Government encouraged people to stay at home; any gathering in public spaces was forbidden, including sporting events and funerals; cancelled or postponed large public events; schools, universities, government offices, libraries, museums, and most shops had to stay closed. Those selling essentials, such as supermarkets or pharmacies, needed to ensure a distance of at least $1 \mathrm{~m}$ between customers. On April 10th the restrictive measures adopted since the beginning of March to contain the Covid19 emergency were prolonged until 3rd May 2020. Such containment measures and changes in social behaviour and awareness have progressively reduced the transmission, and the growth rate of total COVID-19 cases in Italy began slowing [6]. The Italian epidemic curve, as of May 12, is shown in Figure 1.

On 26th April the Italian Prime Minister Giuseppe Conte outlined how the country would begin "Phase Two" of lifting its coronavirus lockdown and announced a gradual easing of the measures starting from May 4th. 


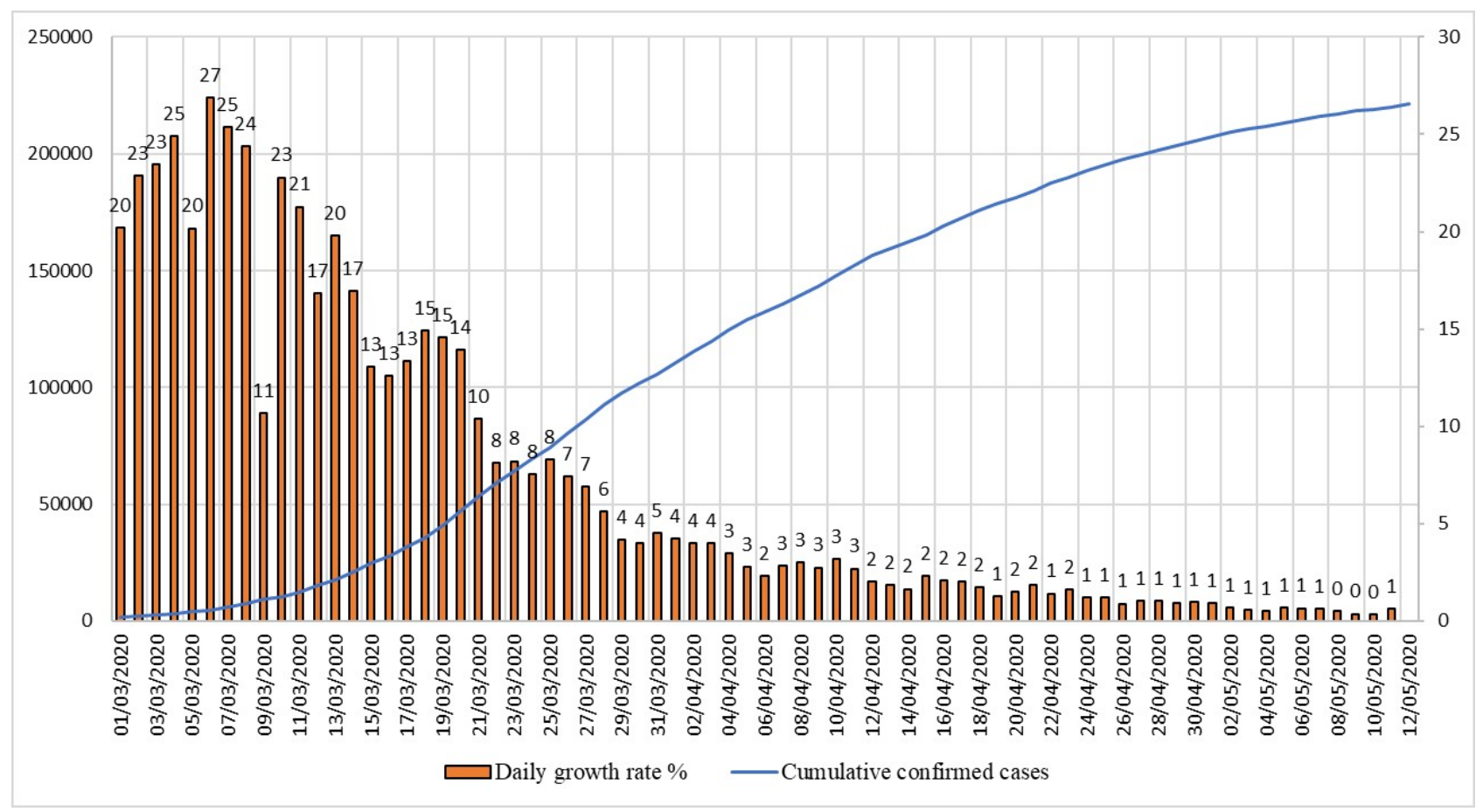

Figure 1: COVID-19 Epidemic curve in Italy. Data source: The Civil Protection Department [7]

The above mentioned chronology of main steps and legal acts taken by the Italian Government for the containment of the COVID-19 epidemiological emergency, allowed us to define 3 fundamental periods for the analysis presented in this paper: Pre-COVID-19 (February 2020); Lockdown period (March-April 2020); "Phase Two" period (After May 4th). Hereafter called as PC, LD, and P2, respectively.

The mobility restriction led to a drastic reduction of urban traffic volumes, with a consequent strong decrease in road congestion, pollutant and noise emissions [9-16]. The study presented in this paper focuses on two principal aspects. Firstly, it shows the effect of urban mobility restriction on urban vehicular traffic using Floating Car Data; then, a noise emission assessment, based on traffic simulation results, is performed in accordance with the CNOSSOS-EU method. Finally, the results of the traffic simulations and road noise maps are presented to examine the traffic-related impacts of containment measures in the city of Rome for the LD and P2 periods.

\section{Methodology}

\subsection{Traffic simulation from FCD}

The first step of the methodology was to evaluate road network traffic volumes in the city of Rome for the periods PC, LP and P2. To this end, a traffic simulation procedure based on Floating Car Data (FCD) was performed. As mentioned by Altintasi et al. [17], the principle of FCD is to collect real-time traffic data, by locating the vehicle via GPS over the entire road network. Data, such as car location, speed and direction of travel are sent to a central processing centre, which uses this information for traffic pattern recognition. FCD used in this study belongs to Viasat S.P.A. and were collected by anonymous vehicles equipped with On Board Unit (OBU) GPS system. The OBU records sequences of location points during the trips with an average frequency of 30 seconds, in addition to the start and stop points, thus storing all the characteristics of the vehicle's path. The total FCD fleet size available in Rome consists of about 22,121 cars, but the size of the circulating FCD fleet is lower and variable, especially during the mobility restriction for the containment of COVID-19.

The use of FCD for traffic modelling and travel demand estimation is widely discussed in literature [18-25]. For the scope of this study, FCD were used to estimate the OriginDestination (O-D) matrices following the procedure intro- 
duced by Eisemann and List [26] and refined by Carrese et al. [27] and Nigro et al. [28]. Five days of observation for each of the three periods (PC, LD, and P2) were analysed to estimate the average O-D trip matrix for the morning peak-hour demand. FCD observations from February 03rd to February 07th were used to estimate the O-D matrix for baseline period (PC); from March 23rd to March 27th for LD; from May 04th to May 08th for P2.

The three scenarios (PC, LD, and P2) were simulated using EMME by INRO, which is a travel demand modelling software. EMME performs a static user equilibrium assignment [29], and provides the traffic volume, the travel time, and the speed for every link of the road network, which was modelled with 1331 centroids (zones) and 81,604 road links. Among these, 322 links represent the Grande Raccordo Anulare (GRA), which is a ring-shaped, $68.2 \mathrm{~km}$ long freeway that encircles Rome [30]. Further developments will deal with the analysis of the evolution over time through the use of a quasi-dynamic simulation [31], whose input are the same used in a static assignment, and with the study along urban arteries affected by traffic signals [32]. The simulations run on an Intel Xeon E5-2640 v3(2.60 $\mathrm{GHz}$ ) processor and all the three scenarios converged (user equilibrium), on average, in 3-5 min.

\subsection{Noise emissions from traffic simulation}

As suggested by Patella et al. [33], the flow (vehicles per hour) and the speed $(\mathrm{km} / \mathrm{h})$ on each link, obtained through the traffic simulation procedure, were used to evaluate the noise emissions for the entire road network in accordance with the Common Noise Assessment Methods in Europe (CNOSSOS-EU) [34], which is the reference calculation model in EU Member States. Chapter III of the CNOSSOS-EU document proposes a classification for types of vehicles, where the general equations and coefficients for the calculation of their sound power emission are reported. There are four currently operational categories $m$ of vehicles type: Category 1- Light motor vehicles; Category 2-Medium heavy vehicles; Category 3 - Heavy vehicles; Category 4 - Powered two-wheelers. In this study the traffic demand was modelled in terms of equivalent-vehicle trips (i.e., a truck has a 'passenger car equivalent' factor of 2.5); therefore, for the sake of comparability between traffic and noise data, it was decided to have the same approach and the same flows on the network were considered for the noise emission calculation using only Category 1 vehicles.

The CNOSSOS-EU method conceptualizes the noise emission of a traffic flow on a link of a network as a line source characterized by its directional sound power, per metre per frequency; which is based on the cumulative sound emissions of individual vehicles in the traffic flow, as a function of speed. The directional sound power per metre per frequency band of the line source $L_{W^{\prime}, \text { eq,line,i,m }}$ (expressed in $\mathrm{dB}$ ) can then be calculated when a traffic flow of $Q_{m}$ vehicles of category $m$ with an average speed $v_{m}$ are known [34]. As per Patella et al. [33], some assumptions were made while applying the CNOSSOS-EU method; more specifically: (a) corrections to the reference conditions were disregarded for the calculation of the $L_{W, i}$ values; (b) a single integrated broadband value $L_{W^{\prime}, e q, \text { line,m }}$ was considered for the analysis, derived from the $L_{W^{\prime}, \text { eq,line,i.m }}$ values computed per frequency $(63 \mathrm{~Hz}-8 \mathrm{kHz})$; (c) the $L_{W^{\prime}, e q, \text { line, } m}$ values were considered as the representative acoustic metrics for the road network links.

\section{Results}

\subsection{Traffic simulation}

The travel demand (O-D matrices) was loaded onto the traffic network of Rome ${ }^{1}$. The total amount of vehicle trips assigned to the network is shown in Table 1 as well as the trucks percentage for each scenario (PC, LD, and P2) and for each AM peak period. Table 1 clearly shows a strong reduction in hourly traffic demand during periods LD and P2 compared to the baseline (PC), on average $-64.6 \%$ and $-34.3 \%$, respectively. Moreover, as a consequence of individual mobility restrictions, the percentage of trunks in the traffic stream significantly increased, on average $+10.7 \%$ for LD and $+1.6 \%$ for P2.

The simulation results of periods $\mathrm{LD}$ and $\mathrm{P} 2$ for the 7:00-8:00 AM peak-hour were compared to the baseline network performances (PC). The following Table 2 summarizes the results in terms of Vehicle Kilometres Travelled (VKT), Total Time Spent (TTS), and average network speed for Intra-GRA roads, which are mainly urban roads, and GRA (freeway).

The traffic simulation results, based on real data detection (FCD), show an overall reduction in the amount of VKT and TTS, more pronounced during the LD, with a consequent increase in network speed. Figure 2 and Figure 3 show the difference in traffic volumes, i.e. the number of vehicles per hour assigned onto the network for the 7:008:00 AM peak-hour demand, between the PC scenario and

1 An overview of mobility-related information of the city of Rome including initiatives to promote the use of public transport as well as innovative solutions for sustainable mobility can be found in [35-38]. 
Table 1: Traffic demand and trucks percentage

\begin{tabular}{cccc}
\hline Scenario & AM peak period & Equivalent-vehicle trips & Trucks (\%) \\
\hline \multirow{3}{*}{ PC (baseline) } & $7: 00-8: 00$ & 342276 & 10.5 \\
& $8: 00-9: 00$ & 307700 & 11.9 \\
& $9: 00-10: 00$ & 314532 & 11.6 \\
\hline \multirow{2}{*}{ LD } & $7: 00-8: 00$ & $112338(-67.2 \%)$ & 23.4 \\
& $8: 00-9: 00$ & $117253(-61.9 \%)$ & 23.8 \\
& $9: 00-10: 00$ & $112119(-64.4 \%)$ & 19.0 \\
\hline \multirow{2}{*}{ P2 } & $7: 00-8: 00$ & $206643(-39.6 \%)$ & 14.9 \\
& $8: 00-9: 00$ & $216106(-29.8 \%)$ & 12.3 \\
& $9: 00-10: 00$ & $211131(-32.9 \%)$ & 11.8 \\
\hline
\end{tabular}

Table 2: Simulation results - The effect of Lockdown and Phase Two on the road network of Rome

\begin{tabular}{ccccccc}
\hline & \multicolumn{2}{c}{ VKT (veh·km) } & \multicolumn{2}{c}{ TTS (veh·h) } & \multicolumn{2}{c}{ Network speed (km/h) } \\
\hline Scenario & Intra-GRA & GRA & Intra-GRA & GRA & Intra-GRA & GRA \\
\hline PC & $1,778,421$ & 988,796 & 87,411 & 23,265 & 20.3 & 42.5 \\
LD & 493,072 & 453,468 & 13,836 & 4921 & 35.6 & 92.1 \\
P2 & 981,785 & 713,027 & 31,899 & 10,167 & 30.8 & 70.1 \\
(LD-PC)/PC & $-72.3 \%$ & $-54.1 \%$ & $-84.2 \%$ & $-78.8 \%$ & $75.2 \%$ & $116.8 \%$ \\
(P2-PC)/PC & $-44.8 \%$ & $-27.9 \%$ & $-63.5 \%$ & $-56.3 \%$ & $51.3 \%$ & $65.0 \%$ \\
\hline
\end{tabular}

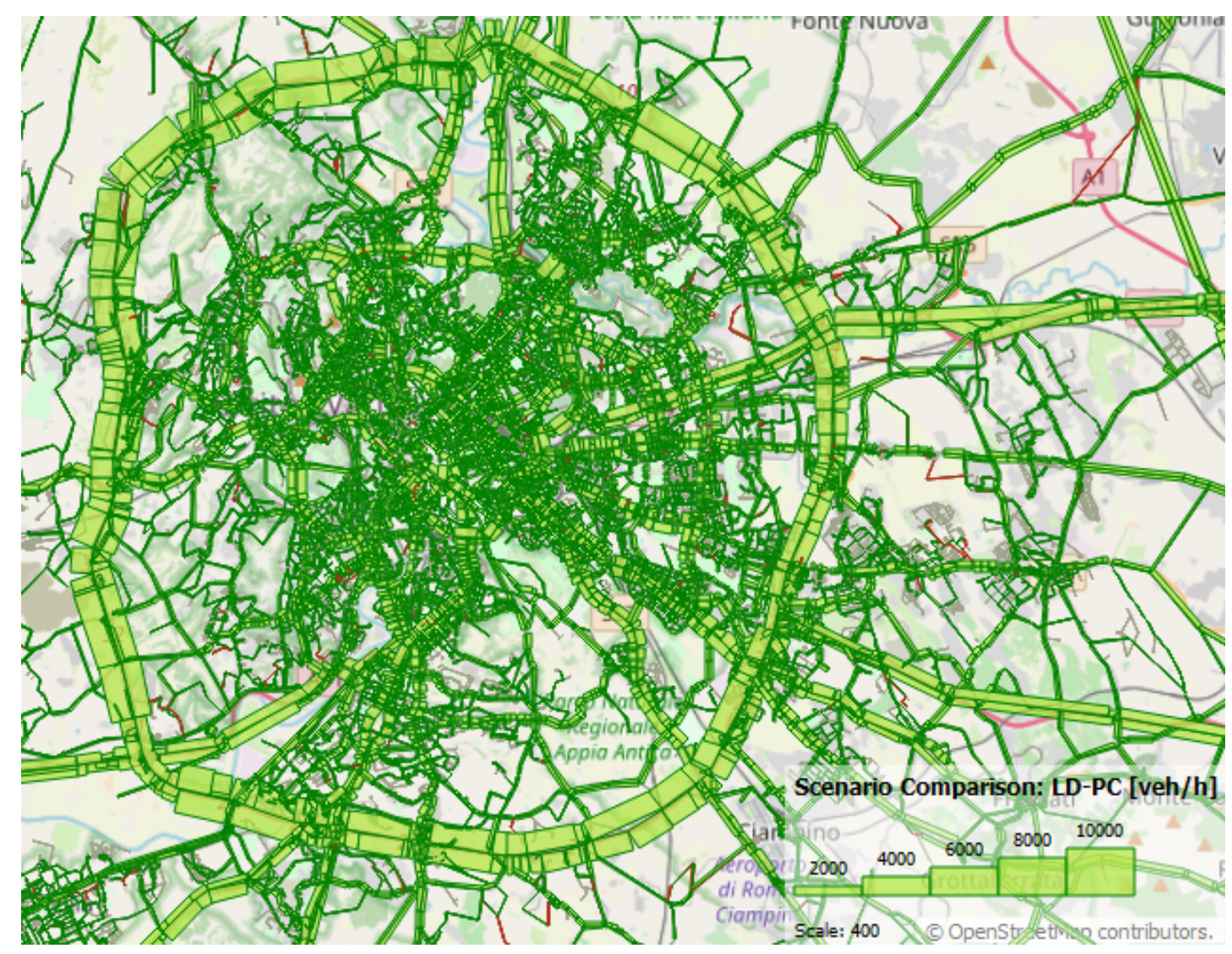

Figure 2: Traffic volume difference (LD-PC), city of Rome 


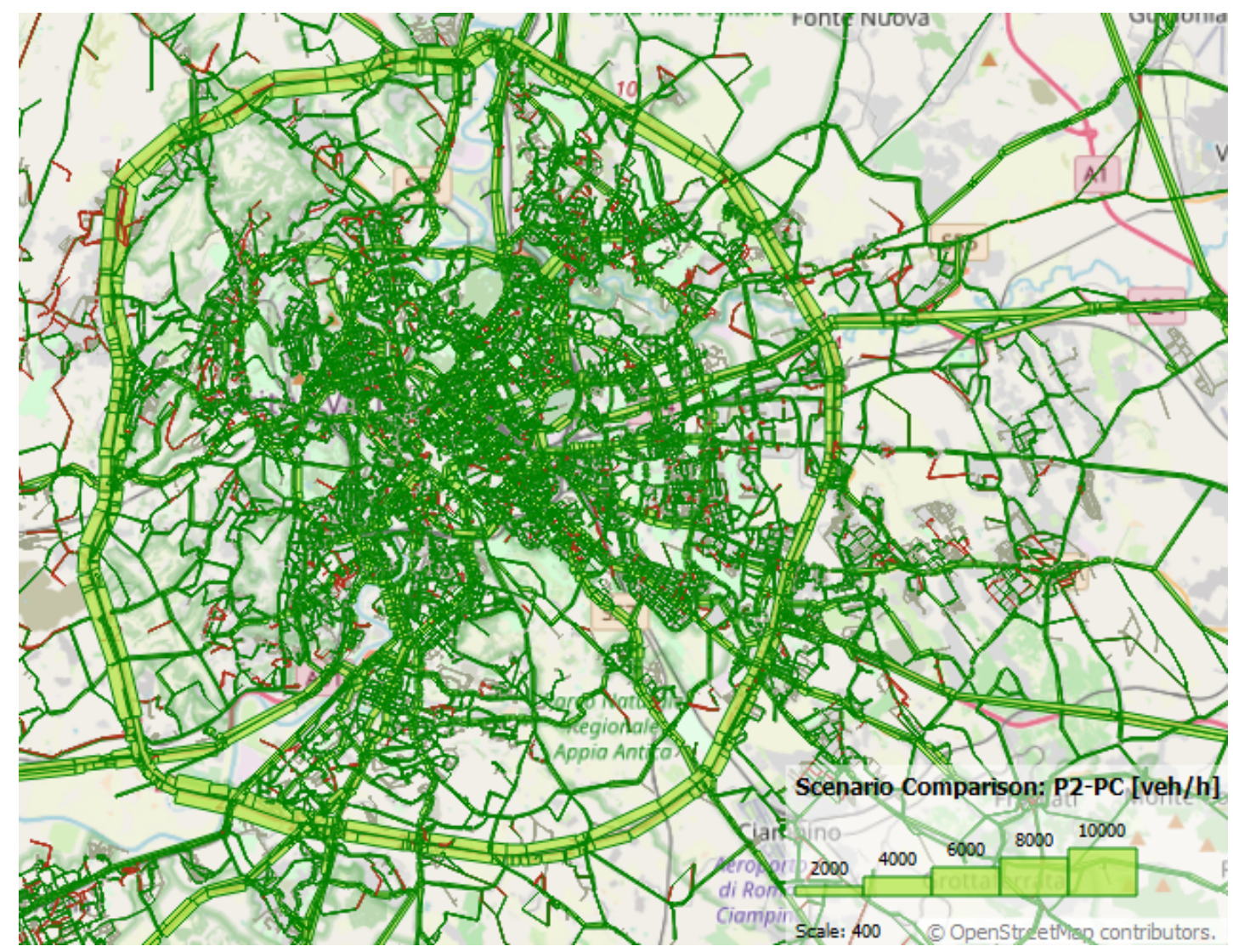

Figure 3: Traffic volume difference (P2-PC), city of Rome

LD and P2 scenarios for each link of the network. A red link means a rise in volumes (positive difference), while a green link means a reduction in volumes (negative difference).

\subsection{Noise emissions simulation}

According to the sections III.2.1, III.2.3, III.2.4, and Appendix III-A of the CNOSSOS-EU guidelines, the noise emission of the traffic flow was calculated for each link of the road network as a source line with a directional sound power per metre per frequency, and those values where then integrated into a single broadband value $L_{W^{\prime}, \text { eq,line, } m}$. Looking at the road network as a whole, Figure 4 shows the distributions of sound power values of the links for the three scenarios. The samples appear to be normally distributed with a clear shift of the peak towards lower $\mathrm{dB}$ levels in the transition from PC to LD, and a rise back to higher dB levels (even if to values still lower than PC) in the transition from $\mathrm{LD}$ to $\mathrm{P} 2$.

However, when controlling for the road type factor (i.e., GRA vs. Intra-GRA category) different patterns of noise emissions emerge. The box-plots reported in Figure 5 provide an overview of the noise emission values observed on the network for the three simulated scenarios, as a function of the road type. For the sample of links from the GRA category, where the noise emissions are higher in general, no particular reduction in emission is observed, with only a slightly wider dispersion in the LD scenario. On the other hand, a noise emissions reduction trend is more clearly observable for the links of the Intra-GRA category, with a similar pattern as per the distributions in Figure 4. This phenomenon is reflected also in Figure 6 and Figure 7 where the maps of noise emission differences are reported between LD and PC, and between P2 and PC accordingly: for the Intra-GRA roads considerable noise emission reductions are experienced, while for the GRA roads noise emission reductions are much smaller, with some links even experiencing small increases in emissions. A possible explanation for this is that on Intra-GRA roads, where speed limits are lower and the volumes of non-essential trips were dramatically reduced, the lockdown measures had a stronger impact on noise emissions. Contrarily, on GRA-type roads (freeway), the reduced volumes of traffic were possibly compensated by the possibility of the fleet of vehicles to use the network at higher speeds (i.e., less 


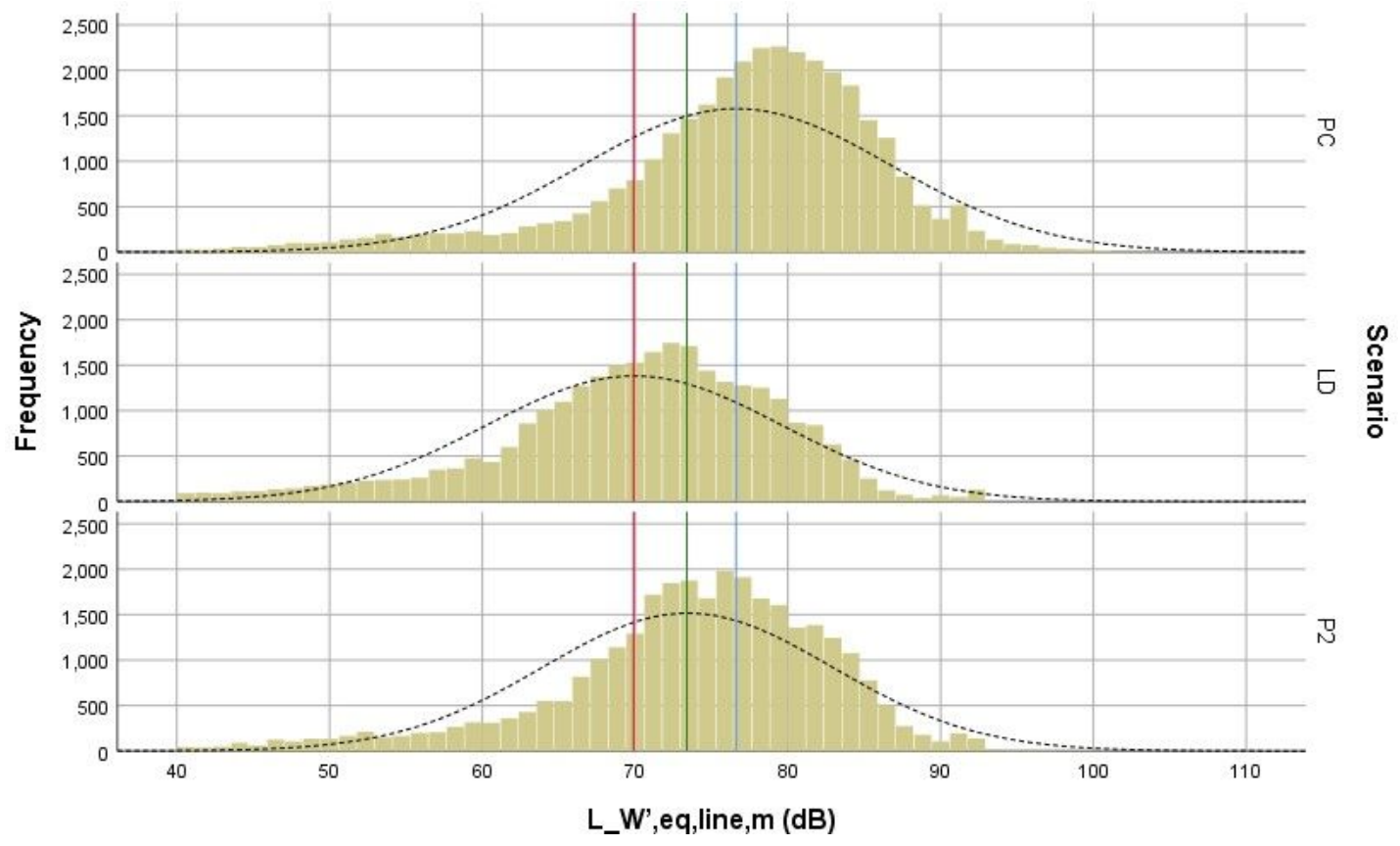

Figure 4: Distributions of the directional sound power per metre values for the three scenarios, and mean values for the three samples: 76.6 $\mathrm{dB}$ ( $\mathrm{PC}$, blue line), $69.9 \mathrm{~dB}$ (LD, purple line), and $73.4 \mathrm{~dB}$ ( $\mathrm{P} 2$, green line)

traffic congestions), thus leading to increased noise emission of the traffic flows.

In order to further explore the effect of lockdown measures on the noise emissions observed on the road network, two separate one-way ANOVAs were conducted (i.e., one for the Intra-GRA sample and one for the GRA sample) to determine if the $L_{W^{\prime}, e q, \text { line, } m}$ values were different in a statistically significant way for the three simulation scenarios: PC (Intra-GRA, $n=33,639$; GRA, $n=308$ ), LD (Intra-GRA, $n=28,225$; GRA, $n=292$ ), and P2 (Intra-GRA, $n=30,411$; GRA, $n=293$ ). Data is presented as mean \pm standard deviation. For the GRA sample, $L_{W^{\prime}, \text { eq, line, } m}$ values were not statistically significantly different between different scenarios, $F(2,890)=1.759, p=.173 . L_{W^{\prime}, e q, \text { line }, m}$ values were actually higher for the P2 scenario $(M=88.5 \mathrm{~dB}, S D$ $=6.0 \mathrm{~dB})$, than for the PC scenario $(M=87.6 \mathrm{~dB}, S D=7.8$ $\mathrm{dB})$ and $\mathrm{LD}$ scenario $(M=87.6 \mathrm{~dB}, S D=7.4 \mathrm{~dB})$. Conversely, for the Intra-GRA sample, $L_{W^{\prime}, \text { eq,line, } m}$ values were statistically significantly different between different scenarios, $F(2,92,272)=3,756.310, p<.001 . L_{W^{\prime}, \text { eq }, \text { line }, m}$ values in this case were higher for the PC scenario $(M=76.5 \mathrm{~dB}, S D=10.1$ $\mathrm{dB})$, compared with the P2 scenario $(M=73.3 \mathrm{~dB}, S D=9.4$ $\mathrm{dB})$ and LD scenario $(M=69.7 \mathrm{~dB}, S D=9.5 \mathrm{~dB})$.

A similar calculation as per the traffic simulation was performed to compare the noise emissions under the PC scenario with the LD and P2 scenarios for the 7:00-8:00 AM peak-hour. Table 3 shows the sound power reduction achieved by implementing the containment measures for

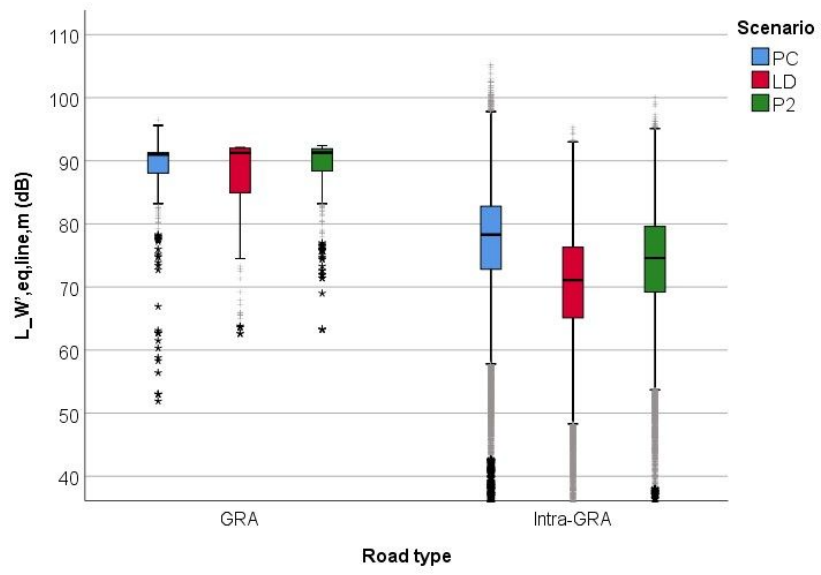

Figure 5: Box-plots of the directional sound power per metre values for the three scenarios (PC, LD and P2) as a function of the road type

private travels and commuting in the LD (stricter measures) and P2 (more relaxed measures) scenarios, depending on the road type (i.e., Intra-GRA or GRA). It is important to note that summing $\mathrm{dB}$ values as it is done for the VKT and TTS is not an established method: results should be treated with caution and considered as an overall indication of decibels that are no longer emitted on the road network [33]. Under such circumstances, it can be observed that noise emission reductions are more obvious for the Intra-GRA road type, for both the LD and P2 scenarios. 


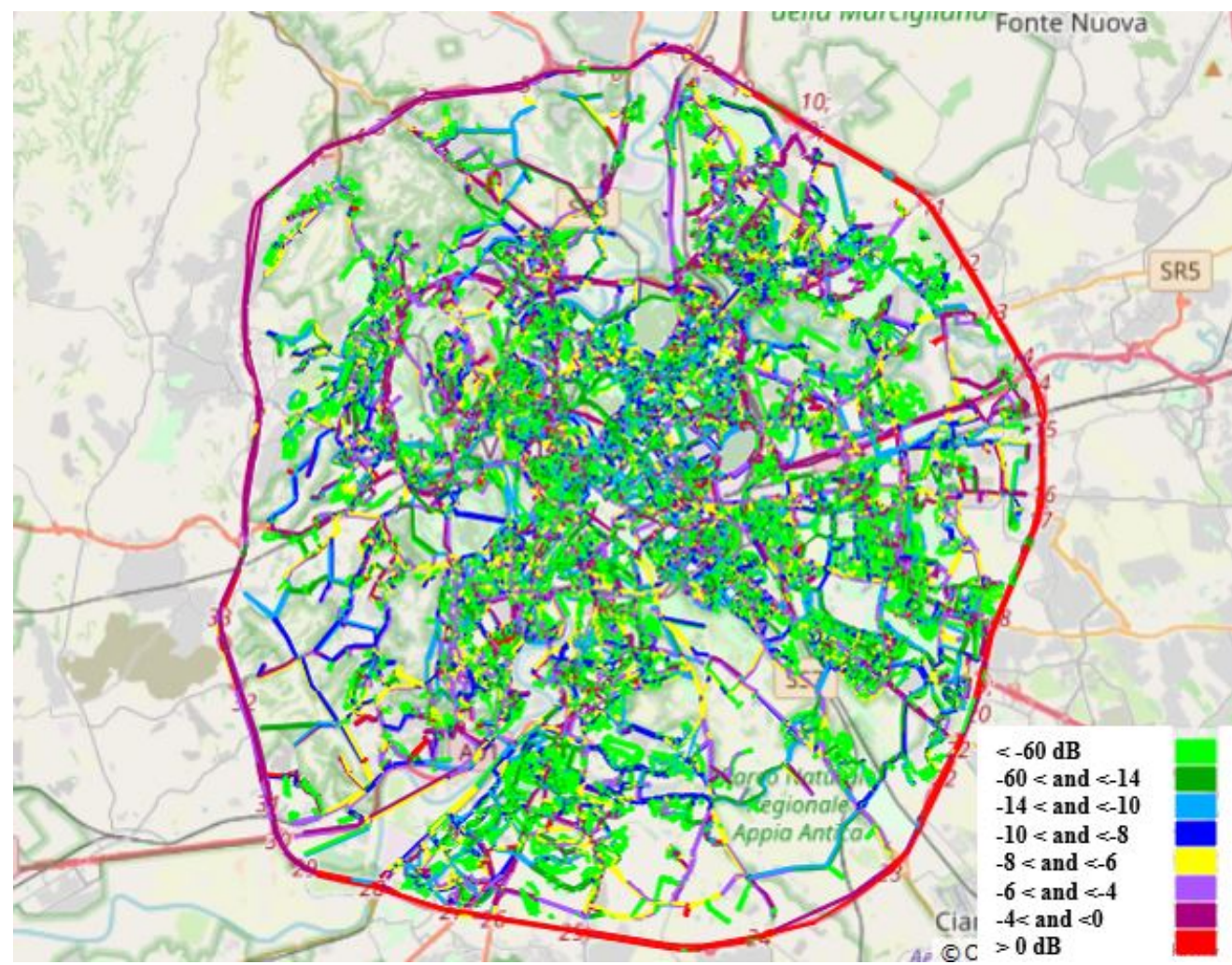

Figure 6: Noise emissions difference (LD-PC), city of Rome

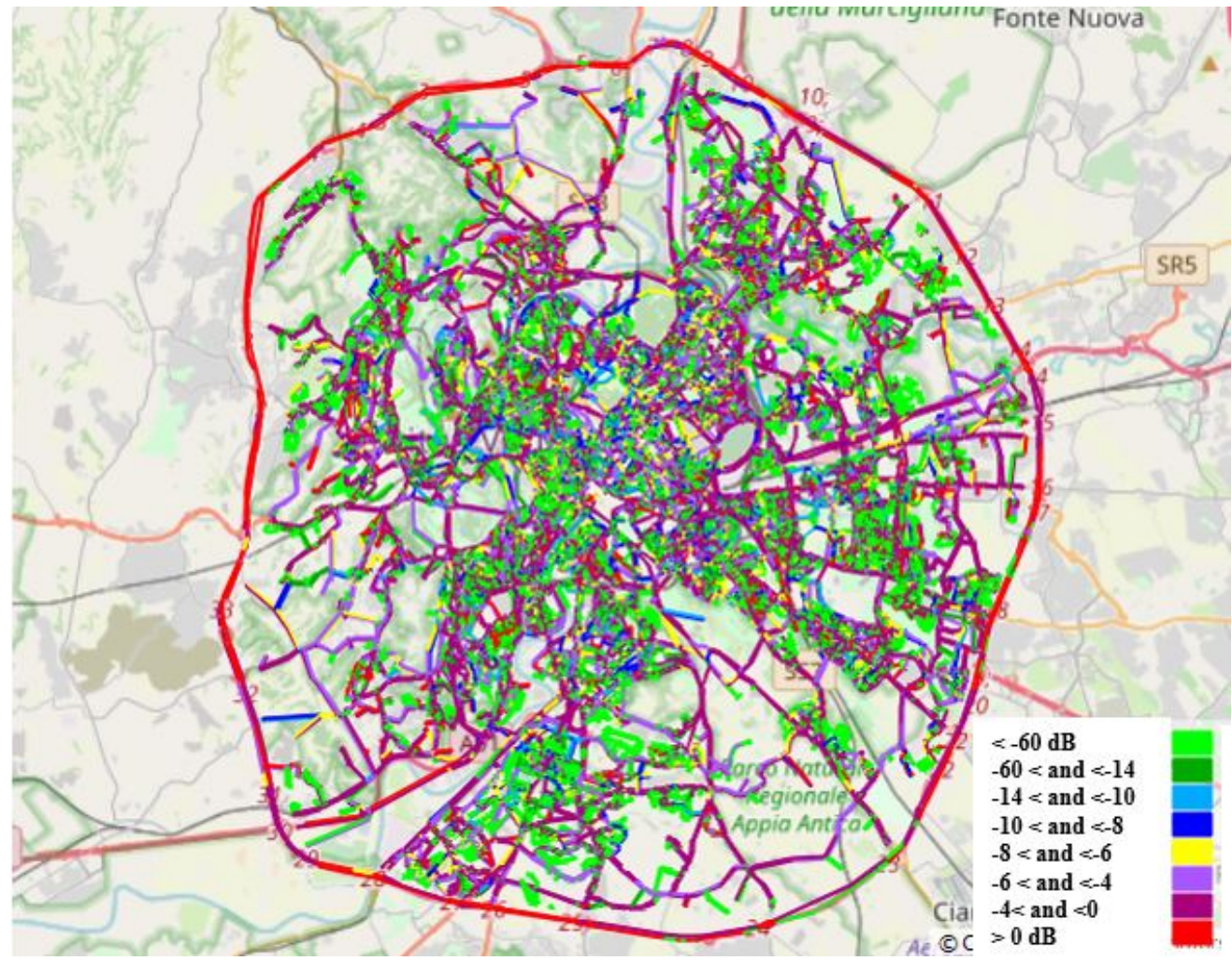

Figure 7: Noise emissions difference (P2-PC), city of Rome 
Table 3: Simulation results - The effect of Lockdown and Phase Two on the noise emissions of the road network of Rome

\begin{tabular}{ccc}
\hline & \multicolumn{2}{c}{ Noise Emissions (dB) } \\
\hline Scenario & Intra-GRA & GRA \\
\hline PC & $2,574,564$ & 26,990 \\
LD & $1,968,822$ & 25,572 \\
P2 & $2,228,546$ & 25,945 \\
(LD-PC)/PC & $-23.5 \%$ & $-5.2 \%$ \\
(P2-PC)/PC & $-13.4 \%$ & $-3.9 \%$ \\
\hline
\end{tabular}

The GRA links are a freeway-like road network: its infrastructure typically suffers from congestions with traffic flows traveling at speeds lower than those allowed. The drastic reduction of traffic volumes led to a general in crease of the network speed with fewer vehicles circulating at higher speeds (possibly closer to the legal speed limit) and less likely of experiencing congestion. Because the CNOSSOS-EU method considers the directional sound power per metre per frequency band of the source line as a function of the traffic flow and its average speed, it is likely that the increased speed compensated the flow reduction, thus leading to much smaller noise emissions reductions. On the other hand, for urban links (e.g., Intra-GRA road type), where the speed limits are much lower the impact of the containment measures is more significant, leading to considerable reductions in noise emissions.

\section{Discussion and conclusions}

The study presented in this paper shows the impact of mobility restriction for COVID-19 containment on urban vehicular traffic and road noise pollution. The proposed approach relies on real time Floating Car Data (FCD), which were used to estimate the Origin-Destination trip matrices for three periods corresponding to the main steps and legal acts taken by the Italian Government for the containment of the COVID-19 epidemiological emergency. During the lockdown period, from 9th March to 3rd May, the private vehicle traffic demand decreased on average by $64.6 \%$, and during the "Phase Two", from May 4th, it decreased by $34.3 \%$. A traffic simulation-based approach was used to evaluate the overall effect of the mobility restriction on road network traffic volumes; a strong reduction in the amount of Vehicle Kilometres Travelled, more pronounced during the lockdown, was found.

Road links traffic volumes and speeds were used as input data for a noise emission assessment performed with the CNOSSOS-EU method. Results showed that noise emission reductions on the road network varied greatly both between scenarios (PC, LD, and P2) and between road types (Intra-GRA and GRA). A general finding is that, compared to the Pre-COVID-19 situation, the noise emission reductions observed on the GRA links are considerably smaller (sometimes negligible) than those observed for the IntraGRA road category (regardless of the level of containment measures). The reason can be attributed to the road types of the network: the GRA is a freeway and a significant reduction in traffic volumes over its link leads to high-speed regime, and therefore, the noise emission reduction generated by a lower flow on GRA links is compensated by the higher emission of the circulating vehicles.

This reflection suggests that some ordinances of traffic limitation to contain pollutant emissions and traffic congestion, which include various regulatory strategies to reduce car travel in the urban context, undoubtedly generate a reduction in traffic-related greenhouse gas emissions, but the noise emissions might not be affected by such measures in some parts of the road networks. For this reason, such policies should be accompanied by appropriate interventions to reduce speed limits on some high-speed road segments.

It is worth noting that in the context of this study, the general noise emission analysis might not be a straightforward representation of the actual acoustic environments as experienced on, or in proximity of, the network of road links, and experimental data would be needed to confirm changes in the acoustic climate $[39,40]$, of which road traffic is only one of the possible sound sources.

Acknowledgement: The authors are grateful to Dr Patrizia Bellucci from the LIFE-DYNAMAP project (http://www.lifedynamap.eu/), for the useful discussion on the GRA noise data.

\section{References}

[1] Livingston E., Bucher K., Coronavirus Disease 2019 (COVID-19) in Italy, JAMA, 2020, 323(14), 1335-1335.

[2] http://www.salute.gov.it/portale/nuovocoronavirus/dettaglioN otizieNuovoCoronavirus.jsp?lingua=italiano\&menu=notizie $\& p=$ dalministero\&id=4736 (accessed 12 May, 2020).

[3] https://amboslo.esteri.it/ambasciata_oslo/en/ambasciata/new s/dall_ambasciata/2020/03/nuove-misure-per-il-contrasto-e .html (accessed 12 May, 2020).

[4] https://www.gazzettaufficiale.it/eli/id/2020/03/08/20A01522/ sg (accessed 12 May, 2020).

[5] https://www.gazzettaufficiale.it/eli/id/2020/03/09/20A01558/ sg (accessed 12 May, 2020). 
[6] http://opendatadpc.maps.arcgis.com/apps/opsdashboard/ind ex.html\#/b0c68bce2cce478eaac82fe38d4138b1 (accessed 12 May, 2020).

[7] http://www.protezionecivile.gov.it/department (accessed 12 May, 2020).

[8] https://github.com/pcm-dpc/COVID-19/tree/master/dati-and amento-nazionale (accessed 12 May, 2020).

[9] Aloi A., Alonso B., Benavente J., Cordera R., Echániz E., González F., et al., Effects of the COVID-19 Lockdown on Urban Mobility: Empirical Evidence from the City of Santander (Spain), Sustainability, 2020, 12(9), 3870.

[10] Collivignarelli M.C., Abbà A., Bertanza G., Pedrazzani R., Ricciardi P., Carnevale Miino M., Lockdown for CoViD-2019 in Milan: what are the effects on air quality?, Sci. Total Environ., 2020, 732, 139280.

[11] Douglas M., Katikireddi S.V., Taulbut M., McKee M., McCartney G., Mitigating the wider health effects of covid-19 pandemic response, BMJ, 2020, 369, m1557.

[12] Mahato S., Pal S., Ghosh K.G., Effect of lockdown amid COVID-19 pandemic on air quality of the megacity Delhi, India, Sci. Total Environ., 2020, 730, 139086.

[13] Nakada L.Y., Urban R.C., COVID-19 pandemic: impacts on the air quality during the partial lockdown in São Paulo state, Brazil, Sci. Total Environ., 2020, 730, 139087.

[14] Sharma S., Zhang M., Anshika, Gao J., Zhang H., Kota S.H., Effect of restricted emissions during COVID-19 on air quality in India, Sci. Total Environ., 2020, 728, 138878.

[15] Wang Q., Su M.A., Preliminary assessment of the impact of COVID-19 on environment - A case study of China, Sci. Total Environ., 2020, 728, 138915.

[16] Zambrano-Monserrate M.A., Ruano M.A., Sanchez-Alcalde L., Indirect effects of COVID-19 on the environment, Sci. Total Environ., 2020, 728, 138813.

[17] Altintasi O., Tuydes-Yaman H., Tuncay K., Detection of urban traffic patterns from Floating Car Data (FCD), Transp. Res. Procedia, 2017, 22, 382-91.

[18] Kerner B.S., Demir C., Herrtwich R.G., Klenov S.L., Rehborn H., Aleksi M., et al., Traffic state detection with floating car data in road networks, Proceedings of IEEE Intelligent Transportation Systems, 2005, DOI: 10.1109/ITSC.2005.1520133.

[19] Ásmundsdóttir R., Chen Y., van Zuylen H.J., Dynamic OriginDestination Matrix Estimation Using Probe Vehicle Data as A Priori Information, Int. Series Operations Research \& Management Sci., 2010, 89-108.

[20] Zhao H., Yu L., Guo J., Zhao N., Wen H., Zhu L., Estimation of Time-Varying OD Demands Incorporating FCD and RTMS Data, J. Transp. Syst. Eng. Inf. Technol., 2010, 10(1), 72-80.

[21] Cao P., Miwa T., Yamamoto T., Morikawa T., Bilevel Generalized Least Squares Estimation of Dynamic Origin-Destination Matrix for Urban Network with Probe Vehicle Data. Bilevel Generalized Least Squares Estimation of Dynamic Origin-Destination Matrix for Urban Network with Probe Vehicle Data, Transp. Res. Rec., 2013, 2333(1), 66-73.

[22] Rahmani M., Koutsopoulos H.N., Jenelius E., Travel time estimation from sparse floating car data with consistent path inference: A fixed point approach. Transp. Res., Part C Emerg. Technol., 2017, 85, 628-43.

[23] Cipriani E., Gori S., Mannini L., Brinchi S., A procedure for urban route travel time forecast based on advanced traffic data: Case study of Rome, Proceedings of the 17th International IEEE Con- ference on Intelligent Transportation Systems (ITSC), 2014, DOI: 10.1109/ITSC.2014.6957809.

[24] Mannini L., Cipriani E., Crisalli U., Gemma A., Vaccaro G., OnStreet Parking Search Time Estimation Using FC, Data. Transp. Res. Procedia, 2017, 27, 929-36.

[25] Vogt S., Fourati W., Schendzielorz T., Friedrich B., Estimation of origin-destination matrices by fusing detector data and Floating Car Data, Transp. Res. Procedia, 2019, 37, 473-80.

[26] Eisenman S.M., List GF. Using probe data to estimate OD matrices, Proceedings of the 7th International IEEE Conference on Intelligent Transportation Systems (IEEE Cat. No.04TH8749), 2004, DOI: $10.1109 /$ ITSC.2004.1398913.

[27] Carrese S., Cipriani E., Mannini L., Nigro M., Dynamic demand estimation and prediction for traffic urban networks adopting new data sources, Transp. Res. Part C Emerg. Technol., 2017, 81, 83-98.

[28] Nigro M., Cipriani E., del Giudice A., Exploiting floating car data for time-dependent Origin-Destination matrices estimation, J. Intell. Transp. Syst., 2018, 22(2), 159-74.

[29] Florian M., Hearn D., Network equilibrium models and algorithms, Network Routing, 1995, 485-550.

[30] Patella S.M., Scrucca F., Asdrubali F., Carrese S., Carbon Footprint of autonomous vehicles at the urban mobility system level: A traffic simulation-based approach, Transp. Res. Part D Transp. Environ., 2019, 74, 189-200.

[31] Fusco G., Colombaroni C., Gemma A., Sardo S.L., A quasidynamic traffic assignment model for large congested urban road networks, Math. Models Methods Appl. Sci., 2013, 7(4), 341-9.

[32] Adacher L., Gemma A., A robust algorithm to solve the signal setting problem considering different traffic assignment approaches, Int. J. Appl. Math. Comput. Sci., 2017, 27(4), 815-26.

[33] Patella S.M., Aletta F., Mannini L., Assessing the impact of Autonomous Vehicles on urban noise pollution, Noise Mapp., 2019, 6(1), 72-82.

[34] Kephalopoulos S., Paviotti M., Anfosso-Lédée F., Common Noise Assessment Methods in Europe (CNOSSOS-EU), Luxembourg: Publications Office of the European Union, 2012.

[35] Carrese S., Giacchetti T., Patella S.M., Petrelli M., Real time ridesharing: Understanding user behavior and policies impact: Carpooling service case study in Lazio Region, Italy, Proceedings of the 5th IEEE International Conference on Models and Technologies for Intelligent Transportation Systems (MT-ITS), 2017.

[36] Carrese S., Giacchetti T., Nigro M., Patella S.M., An innovative car sharing electric vehicle system: an Italian experience, Urban Transport., 2017, XXIII, 245-52.

[37] Patella S.M., Sportiello S., Petrelli M., Carrese S., Workplace relocation from suburb to city center: A case study of Rome, Italy, Case Studies on Transport Policy, 2019, 7(2), 357-62.

[38] Gatta V., Marcucci E., Nigro M., Patella S.M., Serafini S., Public Transport-Based Crowdshipping for Sustainable City Logistics: Assessing Economic and Environmental Impacts, Sustainability, 2018, 11(1), 145.

[39] Bellucci P., Peruzzi L., Zambon G., LIFE DYNAMAP project: the case study of Rome, Appl. Acoust., 2017, 117, 193-206.

[40] Sevillano X., Socoró J.C., Alías F., Bellucci P., Peruzzi L., Radaelli S., et al., DYNAMAP - Development of low cost sensors networks for real time noise mapping. Noise Mapp., 2016, 3(1), DOI: 10.1515/noise-2016-0013. 